\title{
ADVAITA VEDĀNTA: LA NO-DUALIDAD COMO FUNDAMENTO DE LA REALIDAD
}

\author{
Juan Camilo Hernández Rodríguez ${ }^{1}$ \\ Universidad Pedagógica Nacional, Colombia
}

\begin{abstract}
Resumen: con el presente texto pretendo realizar un esbozo general de los conceptos, problemas y principios de la filosofía advaita vedānta; especialmente: la 'no-dualidad' (advaita), el 'Absoluto' (Brahman), y el yo personal o 'alma' (ātman). Para cumplir dicho objetivo, se analizarán estos conceptos; luego, plantearé el problema derivado de la relación entre ellos: la apariencia y el acceso a la realidad a pesar de los límites cognitivos y lingüísticos; $\mathrm{y}$, finalmente, expondré la propuesta de la escuela advaita vedānta. Defenderé que: la escuela advaita no defiende una creatio ex nihilo, es no-dualista, inmanentista y comprende a la liberación del sufrimiento (mokșa) de forma progresiva en el conocimiento (jñāna) para llegar a la unidad ' $y o=$ Absoluto'.
\end{abstract}

Descriptores: Absoluto $\cdot$ No-dualidad $\cdot$ advaita vedānta $\cdot$ Apariencia $\cdot$ Fundamento

Abstract: In this text I intend to make a general outline of the concepts, problems and principles of advaita vedānta philosophy; especially 'non-duality' (advaita), 'Absolute' (Brahman), and personal self or 'soul' (ätman). In order to meet this goal, the paper will analyze these concepts. Then, I will explore the problem derived from the relationship between them: the problem of appearance and access to reality despite cognitive and linguistic limits. Finally, I will present the proposal of the advaita vedānta school about this topic. I will argue that: the Advaita school does not defend a creatio ex nihilo, is non-dualistic, inmmanentist and understands the liberation of suffering (mokșa) progressively in the knowledge (jñāna) to reach the unity 'I=Absolut'.

Keywords: Absolute $\cdot$ Non-duality $\cdot$ advaita vedānta $\cdot$ Appearance $\cdot$ Ground

Enviado: 11/04/2019. Aceptado: 29/07/2019.

\section{INTRODUCCIÓN}

Ciertamente, la mayoría de los filósofos occidentales estarían de acuerdo con Kant (Anth., Ak. VII, 119):

El objeto de estudio más importante al que el hombre puede aplicarse es el hombre mismo, porque él es su propio fin último. El conocerle en cuanto a su especie como

\footnotetext{
${ }^{1}$ Universidad Pedagógica Nacional. E-mail: 1 fl_jchernandezr540@pedagogica.edu.co

ID: http://www.orcid.org/0000-0001-6675-3636
} 
un ser terrenal dotado de razón merece llamarse particularmente un conocimiento del mundo [Weltkentni $\beta$ ], aun cuando el hombre solo constituya una parte de las criaturas terrenales.

Quizás ellos están de acuerdo por la larga tradición subjetivista que se desarrolló gracias al 'yo cartesiano' como certeza primera sobre la cual se puede cimentar el conocimiento del mundo (Descartes Med., AT, VII, 28, 35). Incluso, yendo un poco más lejos, podemos remontarnos al $\Gamma \mathrm{N} \Omega \Theta I$ I $\Sigma$ AYTON ("conócete a ti mismo"), máxima que Platón señala en Charm., 164d; Phaedr., 229e, y que estaba escrita en el Templo del Oráculo de Delfos para ver ese fuerte énfasis que se hace al conocimiento de sí como principio moral y metafísico.

Parece ser que este pensamiento ha sido transversal a lo largo de toda la historia de la filosofía occidental. La relación hombre-mundo ha sido clave para pensarse cualquier pregunta epistemológica; pues con base en las respuestas que se ofrezcan a la pregunta "¿qué relación hay entre lo que soy y lo que es el mundo?" se abren o cierran las posibilidades de ofrecer un conocimiento real de este último.

Tradicionalmente, se nos ha dicho que "La afirmación 'la filosofía es griega en su esencia' no dice otra cosa que: Occidente y Europa, y sólo ellos, son los más originalmente "filosóficos", ${ }^{2}$ Quizás, la razón de ser de esta afirmación está en que los griegos realizaron este descubrimiento (la conciencia del sí mismo como clave para pensarse el mundo) (Husserl, 2008, § 73, Hua. VI, 273). Esta tesis se reafirma en el hecho de que la mayoría (si no es que todos) de los principales manuales de historia de la filosofía -quizás, influenciados por la interpretación de Hegel (cf. Tola y Dragonetti, 2010b, pp. 42; 57-60)- comienzan sus estudios en Grecia, dejando a un lado a las filosofías de la India por considerarlas "no rigurosas" o textos simplemente mitológicos. Dice Hegel (1848), pp. 141-142:

China e India quedan, en cierto modo, fuera de la historia universal, como suposición de los momentos cuya unión vienen a constituir el vivo curso [histórico]. La unidad de la sustancialidad y la libertad subjetiva tienen tal carencia de diferencia y oposición por ambas partes, que precisamente por eso no logra alcanzar la reflexión en sí, la subjetividad. (Trad. propia).

Por otra parte, y a pesar de estas interpretaciones, hoy día suele tener mayor aceptación la idea de que en India hubo sistemas filosóficos serios, rigurosos y valiosos por demás. En gran medida, esto se debe a que cada vez son más los filósofos que se comprometen con el concepto de una 'filosofía perenne' (cf. Huxley, 1954, p. 112) que es posible comprender a partir de los estudios interculturales. Por su parte, sigue siendo necesaria su visibilidad y divulgación de la filosofía de la India en el

\footnotetext{
${ }^{2}$ Heidegger, $2006[W P], 7$. Cursivas fuera del texto.
} 
habla hispana. Por ello, en el presente trabajo mostraré de manera general cómo esa conciencia filosófica de sí y su relación con la conciencia del mundo -que Hegel atribuye exclusivamente a los griegos y alemanes- también tuvo su origen en las Upanișad (textos religiosos [śruti] con amplio contenido filosófico, construidos entre los siglos VII y II AEC); las cuales fueron objeto de reflexión de la filosofía advaita vedānta (principalmente, durante los siglos VIII a IX EC).

Ahora bien, esta exposición del advaita vedānta la realizaré a partir de tres conceptos principales: el 'Absoluto' (Brahman), la 'no-dualidad' (advaita) y la 'apariencia' $(m \bar{a} y \bar{a})$. A partir de estos conceptos indagaré, respectivamente, tres problemas filosóficos que son trabajados transversalmente en la teoría advaita vedānta: 1. ¿Es cognoscible el todo o nuestro entendimiento tiene límites? 2. ¿Puede distinguirse el yo del todo, cuando el yo está contenido necesariamente dentro de ese todo? Y 3. Si nuestro entendimiento es limitado (suponiendo que se ha respondido afirmativamente la primera pregunta), ¿podemos conocer las cosas tal cual son o solo conocemos apariencias de lo que en realidad son las cosas? El primer punto lo explicaré a la luz de los Vedas y el análisis que Tola y Dragonetti (2010a) hacen de ellos; y el segundo y tercero, a partir de las Upanișad y las explicaciones que se pueden encontrar en los comentarios de Gauḍapāda y Śankara. Empero, antes de realizar dicha explicación, es menester realizar un análisis conceptual de los elementos claves en la filosofía advaita vedānta; pues a partir de ello se puede garantizar una mayor claridad en dicha exposición.

\section{ANÁLISIS DE LOS CONCEPTOS: 'BRAHMAN', 'ĀTMAN', 'UPANISTAD' Y 'ADVAITA VEDĀNTA'}

Antes de comenzar el estudio filosófico aclararemos primero algunos conceptos claves: 'ātman' (आत्मन्), 'Brahman' (बरह्मन्), 'advaita vedānta' (अद्वैत वेद़ानत) y 'Upanișad' (उपनषिद्). En primera instancia, 'ātman' es un término amplio, pero puede caracterizarse como "aliento vital, la propia persona; algo real, cierto, verdadero" (Monier-Williams, 1960, voz आत्मन). Algo similar sucede con los conceptos נפש (néfesh) hebreo (Cerni, 1990 [L], Gén., 1:21; 37:21; Job, 41:13 y 20;

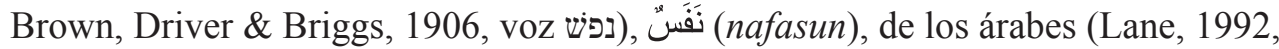
voz نَفَّس (ixtli), para los tlamatinime (filósofos nahuas [aztecas]) (LeónPortilla, 2017, p. 455), $\pi v \varepsilon \tilde{v} \mu \alpha$ griego (Liddell \& Scott, 1996, voz $\pi v \varepsilon \tilde{v} \mu \alpha$ ) y anima latino (Lewis \& Short, voz anima), del cual proviene el término 'alma'. Esta idea de concebir al espíritu o alma como el motor o principio de la vida y movimiento de los seres vivos es central en todas estas tradiciones. De allí que lo hayan caracterizado como "el ser real, estable, permanente", como una oủoía: aquello que tiene la cualidad de permanecer en su ser (Liddell \& Scott, 1996, voz ov̉ бía); es el funda- 
mento de la vida misma. Este "aliento (hálito de vida)" es aquello que adquiere su completud o perfección saliendo de sí y unificándose con la realidad última (el Uno, Dios, Brahman, etc.). Esta teoría fue apropiada por Hegel, para quien el concepto de 'espíritu' (Geist) implica la idea de salir de sí para unificarse con lo universal y así alcanzar su unidad esencial (Hegel, 2017 [EpW], $\S \S 554-556){ }^{3}$

Ahora bien, la traducción directa (y más adecuada) de ātman es: "sí mismo", el "yo personal". Si bien es tentador asociarlo con el espíritu de las tradiciones occidentales, no siempre es aplicable a las tradiciones indias. En la escuela no advaita, por ejemplo, se considera que la ignorancia consiste en la superposición de cualidades en la que se hagan distinciones sujeto-objeto ("yo soy cuerpo", "yo tengo intelecto", etc.) (Martín Díaz, 2000 [Ved. S.], I, 1, int.), incluido el intelecto (buddhi) o el aliento vital ( prāna). En todo caso, sí estaría más asociado al concepto de ov̉oía (lo que es en sí y por sí). Esta idea del àtman como entidad real o superior también se evidencia en el Bhagavad Gītā (Prabhupāda, 2007 [Bhag. Gìtā], XIII, 13 y ss.). Esta posición también la defiende la corriente advaita (Martín Díaz, 2000 [Ved. S.], I, 4, § 3). Es explicado así:

Ese espíritu infinito que como conciencia de la inteligencia (budhi) entre los sentidos, siendo el mismo adopta una apariencia y se mueve entre los mundos. Parece que piensa, parece que se mueve, ya que al identificarse con el sueño profundo trasciende este mundo constituido por las formas de muerte. (Martín Díaz, 2002 [Brh. Up.], IV, 3, § 7). Cursiva propia.

Por otra parte, 'Brahman' (बरह्मन्) podría definirse como “(...) un espíritu impersonal autoexistente, el alma universal (o una esencia divina y fuente por el cual todas las cosas emanan o con el cual todas ellas se identifican y al cual ellas retornan), el que existe por sí, el Absoluto" (Monier-Williams, 1960, p. 738, voz ब्रहमन्). A partir de esta definición, la caracterización más adecuada parece ser la de "Absoluto". 'Absoluto' es un constructo entre ' $a b$ ' y 'solvo', cuyo significado es "liberar, estar desatado, estar irrestricto" (Lewis \& Short, 1956, voz absolvo). La condición del Absoluto es de independencia y completa autonomía; es autosuficiente e ilimitado (como lo muestra la definición). Luego, sus expresiones posteriores (emanaciones, transformaciones, etc.) deben entenderse como acto libre (Tola, $2014[R V], \mathrm{X}$,

\footnotetext{
${ }^{3}$ La discrepancia de Hegel (1848) con la filosofía ortodoxa india (aśtika) radica en el tipo de relación que hay entre el individuo con lo universal: "La concepción india es el absoluto panteísmo universal. A saber, que es un panteísmo de la fantasía, no del pensamiento. Hay una substancia, y todas las individualizaciones son inmediatamente vivificadas y ordenadas en potencias particulares. La materia y contenido sensoriales quedan en lo universal e inconmensurable, tan solo acogidos y superficialmente introducidos; y no son liberados por la fuerza espontánea del espíritu hasta alcanzar una forma bella. No son idealizados en el espíritu, de modo que lo sensorial no hiciera más que estar al servicio de lo espiritual y fuera expresión suya, que tratara de ajustársele; sino que, por el contrario, esto sensorial se extiende a lo inconmensurable e inmenso, con lo cual lo divino se hace extravagante, confuso e infantil" (pp. 171-172. Trad. propia).
} 
$129, \S 4)$. Por esta razón, parece ser el mejor término para explicar la condición del Brahman como ser perfecto, incondicionado y autosuficiente. "Por lo tanto, el nombre que se menciona del Absoluto es el adecuado. Es la Verdad de la verdad. La energía vital es la verdad y Aquello es la Verdad de ella" (Śan̉kara en Martín Díaz, 2002 [Bṛh. Up.], II, 3, 6, kar.).

Ahora bien, ¿qué significa advaita vedānta? Vedānta significa, según Mahadevan (2006), "Veda+anta: final del Veda [...] La palabra sánscrita anta, al igual que con la palabra inglés end, puede utilizarse como 'final' y como "propósito" (pp. 9-10). A su vez, la doctrina filosófica (dárșana) vedānta se desarrolló desde tres escuelas: la dvaita (dualista), viśiștâdvaita (no dualidad calificada) y la advaita (la no-dualista). La más conocida (que es la que trabajaremos acá) es la advaita, cuyos representantes más conocidos son Gauḍapāda y, sobre todo, Śankkara. En esta escuela de la filosofía vedānta se enfocará esta investigación. La filosofía advaita sostiene como tesis principal que la realidad se alcanza cuando se llega a un estado de identidad entre el àtman y el Brahman a través de ciertos tránsitos de unos estados de conciencia a otros.

Por último, es preciso aclarar lo siguiente: si bien es cierto que en el $R g$ Veda ya se puede encontrar en el "Himno de la creación" cierto contenido metafísico, el texto en cuanto tal posee un contenido más religioso que filosófico. Empero, en las tradiciones indias sí se distinguen los textos religiosos de los filosóficos (aunque en algunas ocasiones haya algunos traslapes mutuos, como también pasa en Occidente). En realidad, los textos reconocidos como filosóficos son: las Upanișad, los comentarios que filósofos posteriores (como Gauḍapāda, Śan̉kara, Rāmānuja, etc.) hicieron de estas y los sūtras.

Pero ¿qué son las Upanișad? Upaniṣad es un término intraducible, incluso dentro del mismo sánscrito. Según Deussen (1906), se puede entender como "la doctrina de lo inefable" (pp. 9-12), o, como lo expresa Tola (1999), es “"secreto', 'instrucción secreta', 'doctrina secreta'” (p. 99). En un sentido literal,

El significado etimológico del término 'Upanishad' es 'sentarse (shad) devotamente (ni) cerca (upa)', y es indicativo de la manera en que las doctrinas incluidas en los Upanishad eran aprendidas al principio por alumnos reunidos en pequeños concilios y sentados cerca de sus respectivos maestros. (Mahadevan, 2006, p. 10). ${ }^{4}$

\footnotetext{
4 "De éstos, el (conocimiento) [del Brahman] inferior es el Rg-Veda, el Yajur-Veda, el Sama-Veda, el Atharva-Veda, Fonética, Rituales, Gramática, Etimología, Métrica y Astronomía. El superior es aquel mediante el cual se conoce al Inmutable" (Mahadevan, 2006, Mund. Up., I, i, 5). Aquí se puede evidenciar la distinción entre los textos religiosos (vedas) de carácter más mitológico y donde se nombran varios dioses como personalidades de hechos naturales y los textos filosóficos por los cuales se conoce al Brahman en tanto que entidad metafísica (el Absoluto); en este caso, serían las mismas Upaniṣad y las kārikās (comentarios) de los filósofos de la India.
} 


\section{El Absoluto (Brahman): ¿LO PODEMos Conocer?}

Ahora bien, retomemos nuestra pregunta central: “¿qué tipo de relación hay entre el ātman y el Brahman?". La limitación propia es, quizás, una de las certezas más evidentes que tiene el ser humano de sí mismo. Desde su incapacidad para controlar ciertas situaciones hasta su propia muerte son hechos que, dada su inminencia, han llevado a los filósofos a preguntarse: "Dada mi limitación, ¿qué es aquello que excede esos límites? ¿Lo puedo conocer o, al menos, alcanzar?”. ${ }^{5}$ En India estas reflexiones sobre el Uno (एकम् [Ekam]) fueron tema central de los textos filosóficos ortodoxos. Algo de esto se puede evidenciar en el "Himno a la creación" del $R g$ Veda:

En el comienzo existía tiniebla envuelta por tiniebla. Agua diferenciada era todo esto. Aquel Uno, que estando a punto de devenir, estaba [aún] cubierto por el vacío, nació por la grandeza de su calor [ascético]. En el comienzo le sobrevino [al Uno] el deseo, que fue la primera semilla de la mente. Los Sabios buscando en sus corazones, gracias a su sabiduría encontraron en lo no-existente, el vínculo con lo existente. (Tola, $2014[R V], \mathrm{X}, 129, \S \S 3-4)$.

Quizás este es el segmento más enigmático de esta cita: "encontraron en lo noexistente, el vínculo con lo existente”. ¿Por qué se está indicando esto? Como lo indican Tola y Dragonetti (2010b), “(...) la idea de lo Uno como origen de todo es meramente expresada pero no desarrollada” (p. 98); luego, parece haber un vacío explicativo. Está claro que el Uno es el origen -o, como dice el texto, nacimiento (§ 6)- de todas las cosas. Lo que no queda muy claro es de qué tipo de creación se está hablando aquí. Es más, el mismo texto así lo declara: “¿Quién sabe la verdad? ¿Quién puede decirnos de dónde nació, de dónde esta Creación? Los Dioses nacieron después y gracias a la Creación del Universo. ¿Quién puede, pues, saber de dónde surgió? (...) sólo Aquél [el Uno] sabe de dónde surgió esta creación, ya sea que Él la hizo, ya sea que no - o tal vez ni Él lo sabe" (Tola, $2014[R V], \mathrm{X}, 129, \S 6$ ).

Así explica Śańkara este enigma: “(...) este universo, entendemos, existía antes de su manifestación. Porque una jarra que es inexistente no es percibida siquiera a la salida del sol" (Martín Díaz, 2002 [Brrh. Up.], I, 2, 1, kār.). Y dice más adelante: "Los términos y conceptos "destruido", "producido", "existencia" e "inexistencia" dependen de su carácter doble de manifestación y desaparición" (I, $2,1, k \bar{a} r$.).

Es decir, la génesis no puede entenderse aquí como una creatio ex nihilo, puesto que para la filosofía advaita vedānta el cosmos (ऋत [rta]) estaba potencial-

\footnotetext{
${ }^{5}$ Por razones lógicas, no es posible afirmar que no hay nada más allá de los límites de lo humano, ya que si aceptamos como verdadero que el hombre es limitado (como ya se aceptó), los límites necesariamente denotan un "adentro" y un "afuera" de estos. Si no existiese un "afuera", entonces la noción de límite entraría en contradicción. En ese orden de ideas, la existencia de algo ilimitado debe aceptarse a fortiori.
} 
mente en el Ekam/Brahman. Dice el Rg veda: "Aquel Uno, que estando a punto de devenir, estaba [aún] cubierto por el vacío, nació por la grandeza de su calor ascético" (X, 129, § 3). Luego, no es cierto que no hubiera nada antes de la creación: 1. Existía el Ekam (Uno) mismo; 2. Potencialmente, el universo mismo y su cosmos (rta) ya existía dentro del Uno.

Tola y Dragonetti (2003) afirman que de dos formas se ha entendido este acto creador: como una obra de creación, tal y como sucede al hacer una casa (algo

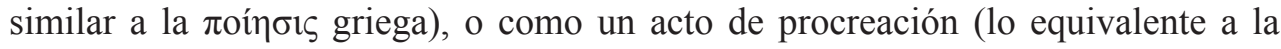
$\gamma \varepsilon ́ v \varepsilon \sigma(\varsigma) .{ }^{6}$ Empero, no tiene cabida hablar de una creación desde la nada. ¿Por qué? Porque, como lo indica el mismo Śankkara, en una u otra acepción, el efecto ya tiene cierto grado de prexistencia (satkāryavāada): en el primer caso, eidética o voluntaria; y en el segundo, seminal o composicional. Por ejemplo: el jarrón prexiste materialmente en la arcilla y el animal prexiste en el semen de su padre y óvulos de su madre (igual que como el queso prexiste en la leche que está a punto de fermentarse) (Martín Díaz, 2000 [Ved. S.], I, 1, 4, kar; 2002 [Br. Up.], I, 2, 1, kār.). ${ }^{7}$

Como lo explica Śankara a partir de dichos ejemplos, "existencia" (सत् [sat]) y "no existencia" (असत् [asat]), no deberían entenderse en términos radicales, sino como "manifestación” y "desaparición". Así, podríamos hablar de relaciones potenciales entre ambos de forma cíclica; lo que también será llamado "samssāra". Luego, ¿no hubo una creación inicial? Sí la hubo, solo que no debe esta ser entendida como una creación radical donde el Ekam creó el mundo y luego de esta creación no volvió a intervenir con su acto creador -algo que sí es característico en la tradición judeocristiana con su séptimo día del génesis-, sino que el Ekam/Brahman debe entenderse como el Absoluto que sostiene, origina y engendra a la naturaleza en su constante paso de la manifestación a la desaparición de forma cíclica (Martín Díaz, 2000 [Ved. S.], II, 2, 7, § 37).

\footnotetext{
${ }^{6}$ Igual que como sucede con la interpretación advaita, las teorías griegas no son compatibles con una perspectiva trascendente (como la judeocristiana); “(...) el Uno, que no puede dejar de engendrar, no puede estar sin aquello que engendra. Y, en este sentido, no es trascendente" (Berti, 2009, p. 51). Cabe, quizás, acá recordar lo que se dice en la Biblia: "Te ruego, hijo, que mires al cielo y a la tierra, y al ver lo que hay en ellos, sepas que a partir de la nada lo hizo Dios y que también el género humano ha llegado así a la existencia" (BJ, 2 Macab., 2:28), remarcando en BJ con una glosa de 'de la nada' (ex

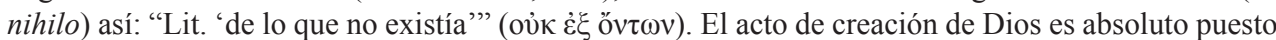
que (bârâ) es un verbo predicable solo a Dios (Aquino, 1951 [ST], I, q. 45, a. 2, sol.); luego, no es equivalente la creación judeocristiana a la $\pi$ oínбıৎ griega ni a la creación védica de la que aquí se habla (cfr. Hernández y Pérez, 2018, p. 51; Hernández, 2019, pp. 480-482).

${ }^{7}$ De igual manera, como se verá en la sección 4, todo lo que implique multiplicidad (incluidas las percepciones, la causalidad, etc.) será entendido como ilusorio (cfr. Gauḍapāda, 1998 [Gauḍ. Kār.], I, 6). En este sentido, más que hablar de una preexistencia del efecto en la causa y una posterior transformación de este primero (satkāryavāda), es más preciso hablar de una aparente transformación que, de hecho, es generada por la superposición que realiza la consciencia al considerar lo múltiple como real (vivartavāda). En este sentido, incluso la causalidad no sería más que otra forma de ilusión.
} 
En este orden de ideas, parece ser que sí es posible comprender apofáticamente y de manera parcial al Uno a partir de la existencia; es decir: lo que no es múltiple: el Ekam/Brahman no es limitado, finito, incompleto, dependiente. Empero, al Absoluto no nos es posible conocerlo como convencionalmente conocemos el mundo; pues es irreductible por nuestra cognición y lenguaje que, por ser y operar desde la multiplicidad, no logran superar las dualidades sujeto-objeto o sujeto-verbo-predicado (o concepto-objeto lógicos). ¿Cómo podemos pensar algo sin características particulares, sin comienzo, sin espacio, atemporal, sin partes, forma, límites, transformaciones, etc.? (Tola y Dragonetti, 2008, p. 321). Dice Śañkara: “¿Cómo se puede describir la Verdad de las verdades mediante esos dos términos 'ni esto, ni esto'? Por eliminación de todas las diferencias debidas a las limitaciones añadidas" (Martín Díaz, 2002 [Brrh. Up.], II, 3, 6, kār.).

Empero, recurrir solo a una via negationis (cfr. Monnier Williams, 1960,

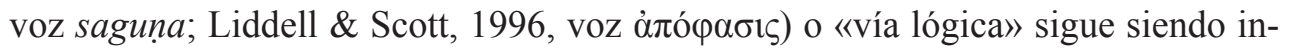
suficiente para la escuela advaita; es necesaria una segunda vía (nirguṇa) en la que podamos alcanzar positivamente al Brahman superando las barreras del lenguaje formal. Así, pues, parece que sigue habiendo fuerte vacío gnoseológico en la relación entre el Uno (Ekam) -luego identificado por en las Upaniṣad con el Brahman (Tola y Dragonetti, 2010b, p. 98)- y el ātman; esto es: la condición misma que tiene el Uno de ser absoluto; es decir, "libre, suelto, incondicionado". No obstante, si el Brahman es la causa del mundo, entonces sí debería haber una relación entre Él y el mundo. ¿Cuál es? A simple vista, la respuesta no parece ser evidente; empero, una vía contemplada por la filosofía de las Upaniṣad es la siguiente: si el Brahman es la verdad, entonces en el mundo hay un rta (orden cósmico) ${ }^{8}$ y este es la verdad que podemos alcanzar (Tola y Dragonetti, 2010b, p. 107).

Empero, ¿cómo podemos alcanzar los seres humanos la verdad (el orden cósmico) si somos sujetos finitos? Investiguemos las dos vías: si concluimos que es imposible alcanzar a la verdad, esto mismo ya constituiría una verdad que, en teoría, ya habríamos alcanzado; lo que implica una contradicción. Luego, la verdad debería ser alcanzable. Pero ¿cómo? ¿Qué proceso debemos realizar nosotros, los humanos, para llegar a esta verdad? Este es el reto filosófico de la filosofía advaita vedānta que investigaremos a continuación.

\footnotetext{
${ }^{8}$ Esta palabra (rta), de hecho, es la raíz del término ratio, el cual proviene de reor-ris (Lewis, Short \& Freund, 1956, voz reor). Su significado es equivalente en muchos sentidos: "juicio, proporción, cálculo, orden, plan, tipo/clase [kind], fundamento, motivo, razón, regla, ley [natural y social]" (voz ratio). Muchas semejanzas hay también entre esta definición y varias de las acepciones del $\lambda$ ó ${ }^{\circ} \varsigma$ grie-

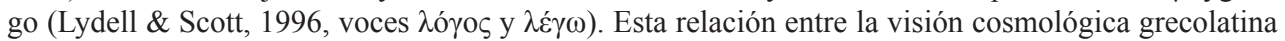

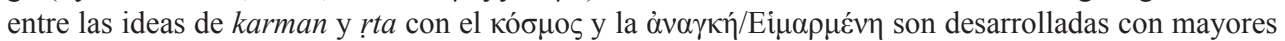
referencias en Tola y Dragonetti (2008, pp. 108-115) y Arnau (2012, p. 24).
} 


\section{LA NO-DUALIDAD (ADVAITA) ENTRE BRAHMAN-ĀTMAN COMO IDENTIDAD}

¿Cómo podemos conocer al Brahman? Según la escuela advaita vedānta, reconociendo al Brahman-ātman en su perfecta unión; es decir, "destituyendo la dualidad, no habiendo duplicidad" (Monier-Williams, 1960, voz अद्वैव).

De este (el Brahman) surge esta enseñanza: esto es, por así decirlo, la luz del relámpago y se ha desvanecido. Así es (la enseñanza) concerniente a los dioses. Ahora (la enseñanza) del yo individual: es hacia el cual la mente parece moverse. Al igual que ese, éste (el yo individual) se recuerda repetidamente como un propósito. (Mahadevan, 2006, Ken. Up., iv, 4-5).

Aquel vacío o abismo entre el Brahman-ātman en la formulación del problema mencionado en la anterior sección es, para la escuela advaita, ilusorio; el ātman, dado que es creado y fundamentado en su existencia por el Brahman, posee en su esencia a Brahman. El Brahman, en tanto que es el Absoluto, está presente en todas las cosas.

(...) [El Absoluto] es tu ser que está dentro de todo. ¿A cuál te refieres? Aquello que respira por la energía vital (prāna) es tu ser que está dentro de todo. Lo que se mueve hacia abajo por la energía (āpana) es tu ser que está dentro de todo. La energía que sale fuera (udāna) es tu Ser que está dentro de todo. Esto es el ser que está dentro de todo. (Martín Díaz, 2002 [Bṛh. Up.], III, iv, 1).

En este sentido, llegamos a la primera conclusión: la escuela advaita vedānta es, efectivamente, inmanentista. No obstante, la valoración de Hegel de que hay un panteísmo que reduce al Absoluto a lo empírico es doblemente errónea. Por una parte, dice Ferrater Mora (1975):

(...) la identificación de Dios con el mundo ha sido afirmada, o dada por supuesta, en varias doctrinas del pasado, tanto orientales (especialmente en India) como "occidentales" (en Grecia, Roma y la Edad Media). Ello no significa que el panteísmo pre-moderno sea igual que el moderno; en rigor, ciertas doctrinas no modernas, orientales y "occidentales", no son rectamente entendidas cuando se las califica de "panteístas" por la sencilla razón de que su "panteísmo" no identifica a Dios con el mundo, sino que parte de una unidad previa que no es posible desgajar en dos aspectos "Dios" y “mundo". (t. 2, pp. 362-363, voz 'panteísmo').

Ciertamente, hay una unidad del todo con el Absoluto, pero no una unificación o identificación, puesto que en principio nunca se concibieron el mundo y el Absoluto como entidades distintas que luego tendrían que ser reconciliadas. En este sentido, el punto de partida del problema solo era aparente; no hay más realidad que el Brahman-ätman. 
Por otra parte, tampoco es cierto que se reduzca a la realidad a lo empírico y contingente; todo lo contrario. Cada una de las cosas múltiples no es, a la larga, más que superposiciones (अधयास $[a d h y \bar{a} s a]$ ) de diferentes cualidades al Absoluto, realizando distinciones del tipo "esto es P y esto no lo es" (). Por eso mismo, antes que una reducción de lo uno a lo múltiple (como sugirió Hegel; cf. supra n.3), es la comprensión de que la realidad no es dual (la multiplicidad, a la larga, no es más que ilusión).

Generalmente, se suele asociar el no-dualismo de la escuela advaita vedānta con cierto monismo. Si bien esta apreciación no es del todo errónea, es preciso clarificar que la cualificación de ese monismo varía entre autores y subescuelas (vādas) (Dīkșita, 1935), que podrían ir desde un monismo idealista a un realismo pluralista, según corresponda (Deussen, 1906). Tomemos solo dos casos: el de Gauḍapāda y el de Śan்kara.

Por una parte, podemos sostener que la realidad es una unidad en la que toda la multiplicidad que percibimos y a partir de la cual diferenciamos (vikalpa) a los entes como cosas distintas a partir de categorías (lo que denominamos antes "superposición" [adhyāsa] es ilusoria o irreal. Desde esta perspectiva metafísica, la realidad es una unidad indiferenciada que, por lo mismo, no puede ser material (puesto que la materia exige multiplicidad locativa, en dimensión, etc.). Por eso mismo, todo intento de multiplicidad es irreal (una proyección ilusoria de la mente [māyā]). Dice Gauḍapāda (1998 [Gaud. k kār.]): "Si la multiplicidad que se percibe existiera, desparecería sin duda. Pero la dualidad no es sino ilusión, ya que la nodualidad es la suprema realidad" (I, 16), explicando después:

Los sabios han declarado que en el sueño todos los objetos son irreales, porque los objetos soñados se sitúan en el interior (del que sueña) y porque tienen un carácter restringido. (...) Las escrituras, apoyándose en la razón, afirman que los carros y demás objetos que se perciben en sueños no existen. Por tanto la irrealidad de las experiencias del sueño queda establecida y demostrada racionalmente. (II, 1; 3).

Pero ¿por qué nos parece tan intuitivo creer que hay múltiples entidades (esta silla, esta mesa, el sol, las nubes, mi cuerpo, etc.)? La explicación que da Gauḍapāda es que gracias a la imaginación (कल्पना [kalpanā]) que se producen internamente ese conjunto de fenómenos (entendidos como póvepov: "lo que se manifiesta a una mente") y nos conducen a la ignorancia derivada de la superposición de unas cualidades a un sujeto que las posee (cf. Timalsina, 2013).

Ahora bien, la postura de Śañkara es similar a la de Gauḍapāda (en término último, ontológicamente solo podemos hablar del Brahman-ātman), aunque nos proporciona dos vías de investigación por medio de las cuales podemos liberarnos de esa superposición de cualidades que nos genera el sufrimiento. En este sentido, 
podemos hablar de nirguna Brahman (lo que el Brahman mismo es [vía afirmativa]); o bien, de saguna Brahman (lo que el Brahman no es, pero se manifiesta parcialmente [vía negativa]). Esta última vía, en la que se da la “(...) eliminación de todas las diferencias debidas a las limitaciones añadidas" (Martín Díaz, 2002 [Brrh. Up.], II, 3, 6, kār.), se conoce como adhyāropāpavāda, ${ }^{9}$ entendido como aquel método según el cual superponemos cualidades al Absoluto para luego negarlas deliberadamente y así alcanzar una "neutralización de la conciencia" (Silberstein, 2017). Puesto que una vía directa del Brahman se vuelve sumamente compleja - aunque, quizás, algunas mentes pudieran lograrlo-, se propone como segunda vía caracterizar al Brahman con cualidades para luego despojarle de ellas y, por así decirlo, verlo en su estado puro; tal cual es. Puesto que las superposiciones (adhyāsa) de cualidades (उपार्धा [upādhi]) reflejan solo aspectos parciales del Absoluto, este método nos permite establecer un puente entre la ignorancia y la realidad última, siendo un medio útil (upāyā) que luego debe ser superado. Así, según mi propia elaboración, tenemos estas dos representaciones: ${ }^{10}$

\section{Esquema 1. Vías de conocimiento del Absoluto en Gaudapāda y Śà̇kara}

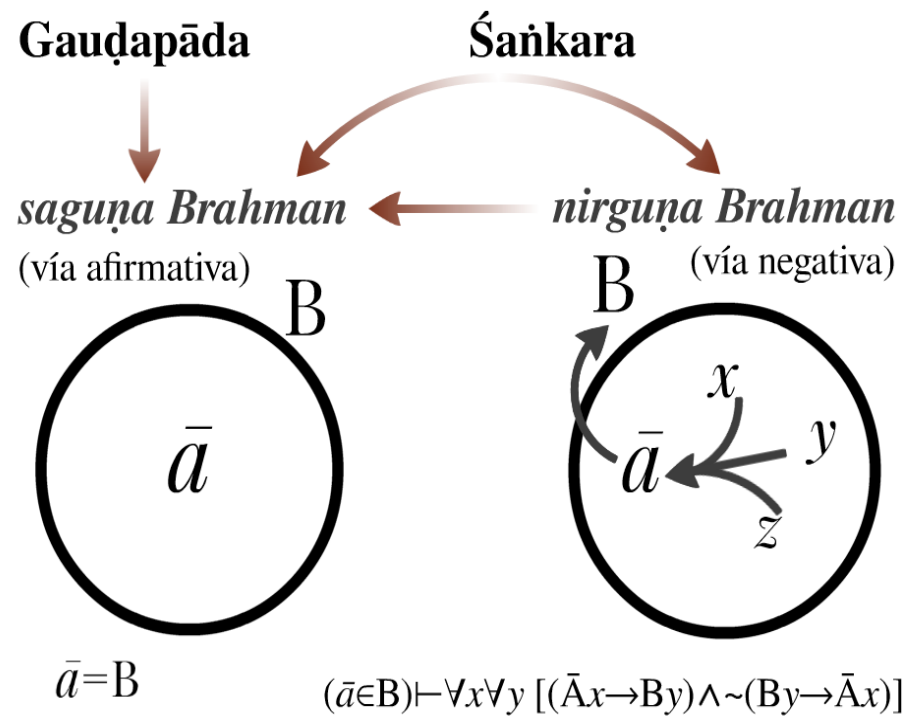

\footnotetext{
${ }^{9}$ Véase una mayor explicación de los métodos de liberación de la ignorancia por parte de las escuelas del vedānta en la obra de Saraswathi Swamiji (2008).

${ }^{10}$ Se podría pensar que Śankara sostiene una postura más moderada que el idealismo de Gauḍapāda, puesto que se acepta un realismo en el que la pluralidad hace parte de la unidad (como se evidencia en la gráfica). No obstante, dado que esto es solo un medio útil (upāya), no queda del todo claro si esta postura provisional tiene algún grado de realidad ontológica o si solo es gnoseológica. Opto más por la segunda postura porque dicha multiplicidad interna la asocio más a la teoría visiștâdvaita de Rāmānuja.
} 
En este orden de ideas, volviendo a la pregunta inicial, no hay genuinamente un vacío entre dos naturalezas, puesto que la realidad es Una y la multiplicidad se genera por ilusiones creadas por la consciencia. A su vez, podemos concebir a la realidad última (el Absoluto) de forma inmediata o mediata, siendo esta última un medio útil para alcanzar el primer grado de consciencia (ver al Absoluto tal cual es). Veremos a continuación de forma un poco más explícita esta segunda vía.

\section{LA APARIENCIA (MĀYĀ) Y LOS DIVERSOS GRADOS DE CONCIENCIA (3\%)}

Hasta el momento hemos explicado el concepto de Brahman como principio absoluto y su relación de identidad por pertenencia con el ātman; empero, hay que explicar un poco mejor cómo es posible el error y la negación de esta dualidad a partir de los diversos grados de conciencia: el Om (30) (también conocido como el símbolo del hinduismo). Esto es explicado en la Māṇ̂ūkya Upanișad: “(...) Y el Ser tiene cuatro cuartos” (Martín, 1998 [Māṇd. Up.], 2), explicado a partir de tres estados y a la realidad última que es transversal a estos. Los estados son:

a) el estado de alerta (वैरावनार [vaiśvānara]), en el cual se contemplan los objetos externos;

b) el estado de sueño (तैजस [taijasa]), en el que se contemplan los objetos internos;

y c) el estado de sueño profundo (पूजजज [prajñ̄a]), en el que no se tiene ningún deseo ni se observa ningún sueño (es el yo puro).

Finalmente, tenemos la realidad última que subyace a esos tres estados y que es liberada de toda superposición de designaciones (upādhis): तुरीय (turīya). En los tres estados el संसार (samsāra: causalidad/reencarnación) se mantiene presente. No obstante, al apercibirse el àtman como el Absoluto, cesa la percepción de la causalidad y, con esta, el sufrimiento. Estos tres estados de consciencia cuentan con los comentarios (kārikā) de Gauḍapāda, el maestro del maestro de Śańkara. Según Gauḍapāda, estos tres estados pueden explicarse en dos niveles distintos: micro y macrocosmos. Cada una de estas manifestaciones es adecuadamente resumida en este cuadro: 
Cuadro sinóptico 1. Diversos estados de conciencia (30) a nivel micro y macrocosmos.

Individual o microcósmico

\begin{tabular}{|c|c|c|}
\hline $\begin{array}{l}\text { Estado } \\
\text { vigilia }\end{array}$ & $\begin{array}{c}\text { Vaiśvānara o viśva }= \\
\text { condición física, "A" del } \mathrm{Om}\end{array}$ & Virāt $=$ manifestación cósmica. \\
\hline $\begin{array}{l}\text { Estado } \\
\text { onírico }\end{array}$ & $\begin{array}{l}\text { Taijasa } \\
=\text { Condición mental, "U” } \\
\text { del } O m\end{array}$ & $\begin{array}{l}\text { Hiranyagarbha }=\text { mente universal. } \\
\text { Hiranyagarbha es la Inteligencia Cósmica, el } \\
\text { Supremo Señor del Universo, también llamado } \\
\text { Brahmâ, Prahna Cósmico y Sutratma. }\end{array}$ \\
\hline $\begin{array}{l}\text { Estado } \\
\text { de sueño } \\
\text { profundo }\end{array}$ & $\begin{array}{c}\operatorname{Praj} \tilde{n} \bar{a}=\text { Condición } \\
\text { intelectual, "M" del } O m\end{array}$ & Iśvara $=$ Causa Primera o Dios. \\
\hline Turīya & \multicolumn{2}{|c|}{$\begin{array}{c}\text { "El cuarto" o Trascendental que se desplaza a través de los estados y conforma } \\
\text { la base del sentido de autoidentidad que se percibe al considerar los cambios de } \\
\text { estado. A pesar de ser llamado el Cuarto, es, en realidad, la Totalidad, siendo el } \\
\text { Brahman-Ätman. Es el aspecto insonoro del Om. }\end{array}$} \\
\hline
\end{tabular}

\section{Universal o microcósmico}

Fuente: Tapasyananda (2003, p. 37).

Cabe recordar esta cita del Bhagavad Gìtā para comprender en términos más prácticos cómo se configura esa relación micro-macrocosmos: "La Personalidad de Dios dijo: Tanto tú como Yo hemos pasado por muchísimos nacimientos. Yo los puedo recordar todos, pero tú no, ¡oh, subyugador del enemigo!" (Prabhupāda, 2007 [Bhag. Gìtā], IV, 5; cfr. Martín Díaz, 2009 [B. Gìtā], IV, 5, kar.). Con esto se hace evidente que el problema en el samsāra no es la reencarnación en cuanto tal (un problema ontológico), sino el hecho de no ser consciente de esta y ser preso de la contingencia y el engaño ( $m \bar{a} y \bar{a})$ que es causa del sufrimiento en este mundo (un problema gnoseológico). Sufrimos por aferrarnos, valorar objetos y estados contingentes y variables; mientras que si orientáramos nuestro yo al Brahman (que somos nosotros mismos), cesaríamos de desear y, con esto, de sufrir. En este orden de ideas, los tres estados no ilustran conocimientos de objetos absolutamente distintos, sino que muestran cómo se avanza de un conocimiento limitado a uno cada vez más amplio hasta llegar al conocimiento absoluto (el Brahman-ätman). Por ello, cada grado de conocimiento o estado inferior está contenido en el mayor y así sucesivamente (véase Esquema 1). 
Esquema 2. Los niveles de consciencia desde la realidad empírica hasta el Brahman-ätman

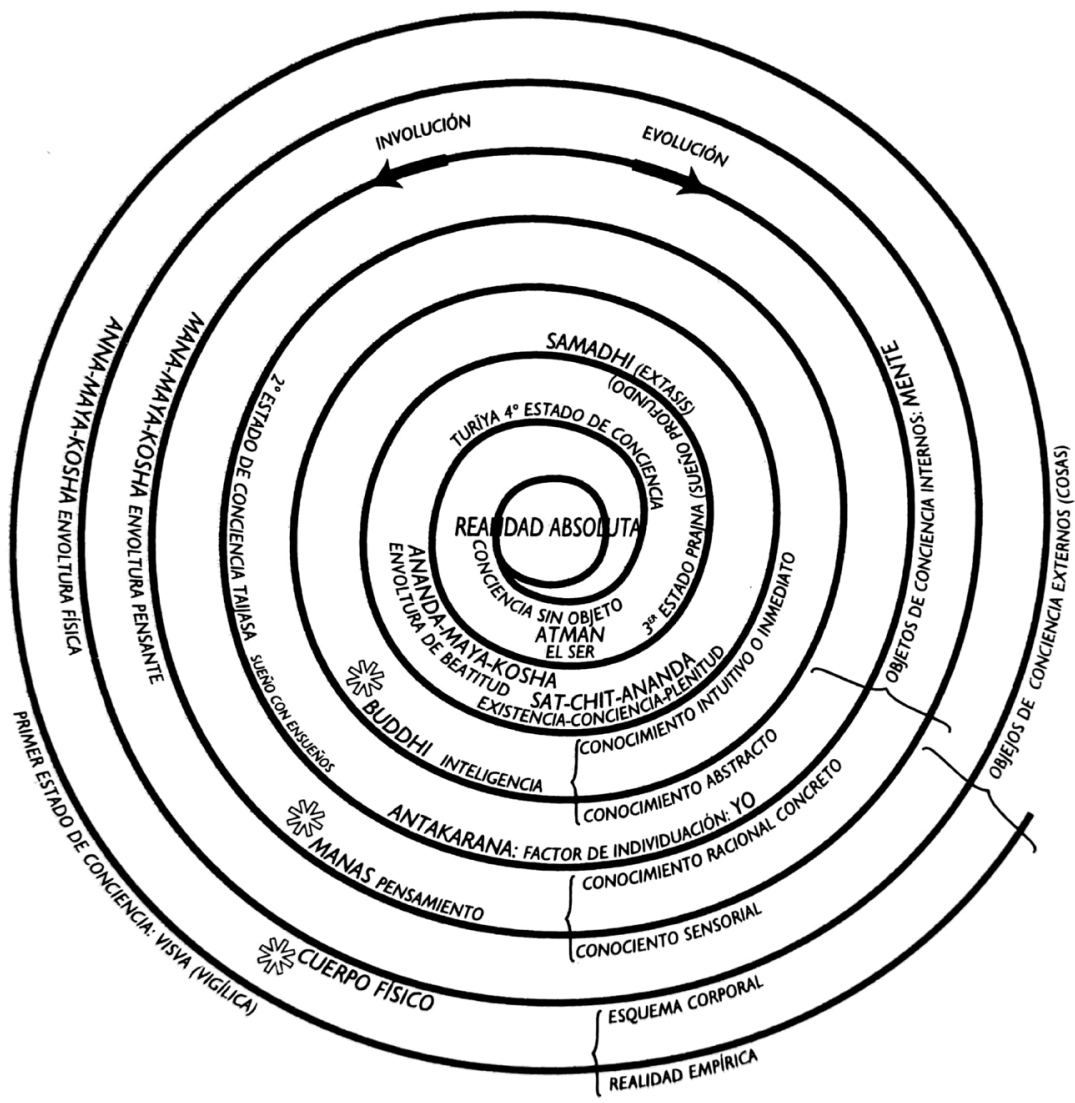

Fuente: Martín Díaz (1998), p. 97.

Este largo trayecto que se evidencia en el anterior esquema es el camino que todo ser humano debe realizar para alcanzar la liberación del sufrimiento. Para los advaitas la liberación es:

(...) por un lado, la desaparición de la imagen errónea que el jīva tiene de sí mismo, de que es diferente de Brahman, de que está sometido a las reencarnaciones, de que es agente de acciones y sujeto de experiencias; $y$, por otro lado, la captación por él de su verdadera esencia y el reconocerse como Brahman. (Tola y Dragonetti, 2008, p. 342).

El segundo criterio parece ser claro: el reconocimiento del àtman como Brahman es la liberación del ätman de la ignorancia (avidyā) y, por ende, del sufrimiento. Empero, lo que no parece quedar todavía claro es el concepto de 'jī $v a$ ' (conciencia corporal/empírica) en esta teoría. 
Recordemos el anterior cuadro: en las tres primeras etapas todavía la consciencia no se había liberado de la causalidad; en la última, esta dualidad se superó. La teoría clásica india sobre la liberación del àtman del samsāra es considerada dentro de la tradición vedānta como un paso anterior (quizás, necesario) para la liberación (mokșa), pero le parece insuficiente. Más aún, una vez se llega al último estado de consciencia, el àtman logra darse cuenta de que esos tres momentos anteriores seguían siendo $m \bar{a} y \bar{a}$ y, por ello, permanecía en la ignorancia. En tres primeros momentos el yo personal es considerado en la escuela advaita como jīva: "el principio de la vida, aliento vital, la vida del alma personal (que se distingue del alma universal)" (Monnier Williams, 1960, p. 422, voz जीव). El jīva se distinge del ätman en cuanto este primero sigue reconociéndose como distinto del espíritu universal (el Brahman); el ätman, por otra parte, no. ${ }^{11}$ Pero, ¿cuál es la causa de esa ignorancia? Dice Śankara:

El dolor es deseo. La disconformidad que se siente cuando se piensa en alguna cosa conveniente es la semilla del deseo. Porque nos afligimos con la ambición a causa del desagradable deseo. Mientras la ilusión es un error, una confusión que surge por una noción falsa, es la ignorancia la fuente total de todos los problemas. (Bṛh. Up., III, 5, 1, kār.).

Así, pues, se puede plantear una relación tríadica de tres obstáculos para la liberación del ätman de la ignorancia de la que él mismo se ha puesto preso: la ignorancia, el deseo y la acción. Puesto que por la ignorancia (अवद्विया [avidyā]) nos concebimos como sujetos finitos, nos pensamos como seres carentes y, por lo mismo, deseamos (तृषण [trș̣na]) llenar esa carencia de alguna forma. Finalmente, se llena esa carencia por medio de la realización de ese deseo y obtener algún resultado o fruto que, a su vez, por medio de ciertos residuos representacionales (वासनास् [vāsanās]), nos tendría condicionados a la ignorancia. Ahora, la única forma de liberarse de ese ciclo es por medio del progresivo ejercicio cognitivo de reflexión y autoconsciencia de sí mismo por los estadios anteriormente mencionados. Para la escuela advaita, las buenas acciones son insuficientes para la liberación, puesto que podemos actuar bien y eso no nos libera del deseo futuro (Sureśvara, 1988).

Lo anterior no quiere sugerir que no se hagan buenas acciones, sino que no son medios eficaces para la liberación. El vedantín no está en contra de los rituales, sino que, a pesar de hacerlos, sabe que solo la meditación y el ade-

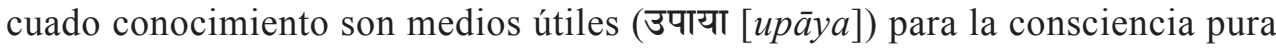

\footnotetext{
${ }^{11}$ Como se dijo en la definición, àtman puede ser cualquier manifestación del sí mismo; no obstante, el verdadero àtman es aquel indiferenciado de la realidad última. Por eso mismo, el jīva no es el genuino àtman.
} 
(Martín Díaz, 2000 [Ved. S.], IV, 3, 6, kar.; Martín Díaz, 2009 [Ken. Up.], int. Śan.). Luego de comprender que todo ello sigue siendo ignorancia, comprende su ineficacia. “(...) La sabiduría sobre el Absoluto es contraria a los ritos y se considera independiente. Porque no es el efecto de ninguna cosa, útil para la más elevada finalidad humana e independiente de cualquier factor auxiliar". ([Ved. S.]., IV, 3, 1, kār.). ${ }^{12}$

\section{Conclusiones}

Recordemos la ruta realizada en esta explicación de la filosofía advaita vedānta: 1. La metafísica advaita vedānta no se sustenta en una creación desde la nada, sino que, más cercana a una teoría emanacionista, se afirma que el efecto preexiste en la causa; y, más aún, en término último, la causa y el efecto (o, la causalidad misma), solo es una ilusión. 2. La filosofía advaita vedānta sostiene como tesis principal que la relación entre Brahman y ātman es de no-dualidad; por ello, el conocimiento de la realidad se alcanza cuando la consciencia del àtman se libera de (renuncia a) los contenidos del mundo exterior creados por su imaginación y llega a cierto estado de neutralización de la consciencia. 3 . Para alcanzar ese estado es necesario que el ātman realice el tránsito de un estado de consciencia a otro superior donde cada vez este (el àtman) adquiera una comprensión más amplia (menos limitada) del mundo hasta llegar a la unidad Brahman-ätman. 4. El ātman solo logra liberarse de manera definitiva del sufrimiento cuando se percata de que todo lo vinculado con el samsāra (acciones, deseos, intereses, causalidad, tiempo, muerte, etc.) son pura apariencia (māy $\bar{a})$. Ello no indica que la perspectiva neutralista del advaita vedānta sea rival de la tradición que defiende el karma, sino que una vez logra superarle, se da cuenta de que todo ello era pura ilusión. En este sentido, el discurso (incluso este) debe ser entendido como un medio útil que luego debe ser abandonado tras el descubrimiento de la identidad pura entre yo-Absoluto, ya que ¿una vez comprendida la realidad última, qué necesidad tenemos de aferrarnos a algo? En esto consiste, pues, la renuncia del vedantín.

\footnotetext{
${ }^{12}$ Como se ve en Isayeva (1993), aquí está la mayor diferencia/disputa entre la escuela pūrva-mimāmsāa y la uttara-mimāmsāa (es decir, la escuela vedānta) (p. 199); mientras la darśana uttara-mīmāmsāa sostiene que los rituales y la interpretación de los textos son sagrados y la única vía de la liberación del àtman, Śankara sostiene abiertamente la inutilidad que en términos últimos eso representa. Esta oposición no es absoluta; quizás podría aceptarse algún beneficio provisional; es un medio útil (upāya). Empero, lo que sí tiene claro Śankara es que los rituales siguen siendo prácticas que refuerzan la dualidad y, por ello, obstaculizan, después de cierto momento, la liberación (cfr. Martín Díaz, 2000 [Ved. S.], III, 4, 1, kar.).
} 


\section{BIBLIOGRAFÍA}

Aquino, s. T. (1951): [ST] Summa theologice. Prima pars. Madrid: BAC.

Arnau, J. (2005): La palabra frente al vacío: la filosofía de Nāgārjuna. México: FCE.

Arnau, J. (2011): “Introducción”. Fundamentos de la vía media (pp. 11-46). Madrid: Siruela.

Arnau, J. (2012): Cosmologías de la India. Védica, sāmkhya y budista. México: FCE.

Berti, E. (2009): En el principio era la maravilla. Las grandes pregunta de la filosofía antigua. Trad. Helena Aguilà. Madrid: Gredos.

Biblia de Jerusalén. 2014 ed. Trad. José Ángel Ubieta. Bilbao: Descleé de Brower.

Brown, F., Driver, S. \& Briggs, C. (1906): Hebrew and English Lexicon of the Old Testament. Oxford: Oxford University Press. (http://www.ericlevy.com/revel/bdb/bdb/main.htm).

Cerni, R. (1990). Antiguo Testamento interlineal hebreo-español. Tomo 1. Bogotá: Clie.

Cross, S. (2013): "Metaphysical Factors behind the Empirical World: Advaita Vedanta", Schopenhauer's encounter with Indian Thought: Representation and Will and their Indian Parallels (pp. 132-147). Honolulu: University of Hawaii Press.

Descartes, R. (2014): Meditaciones acerca de la Filosofía Primera. Trad. Jorge Aurelio Díaz. Edición trilingüe. Bogotá: Universidad Nacional de Colombia.

Deussen, P. (1906): The Philosophy of the Upanishads. Edinburg: T. \& T. Clark.

Deutsch, E. \& Dalvi, R. (Eds.) (2004): The Essential Vedānta. Bloomington: World Wisdom.

Dīkșita, A. (1935). Siddhāntaleśasañgraha. Trans. S. S. Suryanarayana Sastri. Vol. 1. Chennai: University of Madras.

Ferrater Mora, J. (1975): Diccionario de filosofía. Tomos 1 y 2. Buenos Aires: Sudamericana.

Hegel, G. W. F. (1848): „Vorlesungen über die Philosophie der Geschichte“. Im: Georg Wilhelm Friedrich Hegels Werke. Volständige Ausgabe. Dritte Auflage, von Karl Hegel. Berlin: Verlag von Dunker und Humblot.

Hegel, G. W. F. (2017): [EpW] Enciclopedia de las ciencias filosóficas. Trad. Ramón Vals Plana. Edición bilingüe. Madrid: Abada.

Heidegger, M. (2006): [WM] ¿Qué es la filosofía? Trad. Jesús Escudero. Barcelona: Herder.

Hernández Rodríguez, J. C. (2018): "Respuestas a las paradojas sobre la omnipotencia de Dios”, Pensamiento, № 75 (283), 469-485. DOI: 10.14422/pen.v75.i283.y2019.026

Hernández, J. C. y Pérez, J. (2018): “Choque de paradigmas: análisis a las prohibiciones de Tamburini y Retz a diversas tesis modernas”, Cuadernos de Filosofía Latinoamericana, № 39 (119), 47-76. DOI: http://www.doi.org/10.15332/25005375.5050.

Husserl, Edmund. Crisis de las ciencias europeas y la fenomenología trascendental. Trad. Julia V. Iribarne. Buenos Aires: Prometeo, 2008.

Huxley, A. (1954). Introduction to The Song of God, Bhagavad Gita. New York: The New American Library. 
Isayeva, N. (1993): Shankara and Indian Philosophy. NY: State University of New York Press.

Kant, I. (2014): „Antropologie in pragmatischer Hinsicht“. En: Antropología en el sentido pragmático. Ed. bilingüe. México: Fondo de la Cultura Económica.

Lane, E. W. (1992): Arabic-English Lexicon. Cambridge, UK: Islamic Texts Society. (http:// lexicon.quranic-research.net/).

León-Portilla, M. (2017): La filosofía náhuatl estudiada en sus fuentes. México: UNAM.

Lewis, C. T., Short, C. \& Freund W. (1956): Latin Dictionary by Lewis \& Short, Founded on Andrew's Edition of Freund's Latin Dictionary. Oxford: Oxford University Press.

Liddell, H. G. \& Scott, R. (1996): Greek-English Lexicon. Oxford: Oxford Clarendon Press.

Mahadevan, T. P. M. (Ed.). (2006): Los Upanishads esenciales. México: Lectorum.

Gauḍapāda. (1998): [Gauḍ. Kār.] "Kārikā de Gauḍapāda". En: Martín Díaz, C. (Ed. y trad.). Conciencia y Realidad. Estudio sobre la metafísica advaita con la Māṇ̣ūkya Upanișad, las kārikā de Gauḍāāda y comentarios de Śankkara (pp.115-216). Madrid: Trotta.

Martín Díaz, C. (Ed. y trad.). (1998): [Mān. Up.] Conciencia y Realidad. Estudio sobre la metafísica advaita con la Māṇ̂ūkya Upanișad, las kārikā de Gauḍapāda y comentarios de Śankara. Madrid: Trotta.

Martín Díaz, C. (Ed. y trad.). (2000): [Ved. S.] Brahma-Sūtras Upaniṣad con los comentarios advaita de Śankara. Madrid: Trotta.

Martín Díaz, C. (Ed. y trad.). (2002): [Bṛh. Up.] Gran Upaniṣad del Bosque Upaniṣad con los comentarios advaita de Śankkara. Madrid: Trotta.

Martín Díaz, C. (Ed. y trad.). (2009): [BG] Bhagavad Gītā Upaniṣad con los comentarios advaita de Śankara. Madrid: Trotta.

Martín Díaz, C. (Ed. y trad.). (2009): Upaniṣad con los comentarios advaita de Śankara. Madrid: Trotta.

Matilal, B. K. (1986). Perception: An Essay of Classical Indian Theories of Knowledge. Oxford: Oxford Clarendon Press.

Monnier-Williams, M. (1960): Sanskrit-English Dictionary [rev. 2008]. Oxford: Oxford Clarendon Press. (http://www.sanskrit-lexicon.uni-koeln.de/monier/).

Nāgārjuna. (2011): [MK] Fundamentos de la vía media. Trad. Juan Arnau. Madrid: Siruela.

Platón. (2010a): [Charm.] Cármides. En: Obra completa. (Trad. Emilio Lledó). Biblioteca de Grandes Pensadores. Alegre Gorrí, A. (Ed.) Madrid: Gredos.

Platón. (2010c): [Phaedr.] Fedro. En: Obra completa. (Trad. Emilio Lledó). Biblioteca de Grandes Pensadores. Alegre Gorrí, A. (Ed.) Madrid: Gredos.

Plotino. (2002): [Enn.] Enéadas. (Trad. Jesús Igal). Madrid: Gredos.

Prabhupāda, C. B. (Ed. y Trad.) (2007): [BG] El Bhagavad-gītā tal como es. Edición crítica bilingüe. Bogotá: Bhaktivedānta Book Trust.

Silberstein, M. (2017): "Panentheism, Neutral Monism, and Advaita Vedanta". Zygon, N०52, 4. pp. 1123-1145. 
Sri Satchidanandendra Saraswathi Swamiji. (2008). Essays on Vedanta. Karnataka: Adhyatma Prakasha Karyalaya.

Sureśvara. (1988). Naiṣkarmyasiddhi. Ed. y trans. R. Balasubramanian. Chennai: University of Madras, Radhakrishan Institute for Advance Study in Philosophy.

Tapasyananda, S. (2003): "Resumen del Mândûkya Kārikā". En: Sarvananda, S. El Mândûkya Upanishad. Trad. Ada D. Albrecht. Buenos Aires: Editorial Hastinapura.

Timalsina, S. (2013): “Gauḍapāda on Imagination”. J Indian Philos, N 41. pp. 591-602. DOI: 10.1007/s10781-013-9203-6.

Tola, F. (1999): "Filosofía de la India I. Vedismo, Brahmanismo, hinduismo". En: Cruz, Hernández, M. Filosofías no Occidentales (pp. 97-136). Madrid: Trotta.

Tola, F. (2014): [RV] Himnos del Rig Veda. (Ed. y trad.). Madrid: Las Cuarenta.

Tola, F. y Dragonetti, C. (2010a): "El vedismo. Los Vedas, lo Uno como origen de todo. El orden cósmico". Asociación Española de Orientalistas, N 31. pp. 217-241.

Tola, F. y Dragonetti, C. (2010b): La filosofía de la India. Del Veda al Vedānta. El sistema Sāmkhya. El mito de la oposición entre el "pensamiento" indio y "filosofía" occidental. Barcelona: Kairós. 